\title{
Effects of Saccharomyces cerevisiae cell wall addition on feed digestibility, fecal fermentation and microbiota and immunological parameters in adult cats
}

Laura Fantucci de Oliveira Matheus ${ }^{1}$, Larissa Wunsche Risolia ${ }^{1}$, Mariane Ceschin Ernandes ${ }^{1}$, Johnny Maciel de Souza', Patrícia Massae Oba², Thiago Henrique Annibale Vendramini ${ }^{1}$, Vivian Pedrinelli ${ }^{1}$, Lucas Ben Fiuza Henríquez' , Cristina de Oliveira Massoco ${ }^{1}$, Cristiana Fonseca Ferreira Pontieri ${ }^{3}$ and Marcio Antonio Brunetto ${ }^{1 *}$

\begin{abstract}
Background: This study aimed to evaluate the effects of increasing dosages of a commercial product composed by Saccharomyces cerevisiae yeast (YAM), with active metabolites, which are beta glucans, nucleotides, organic acids, polyphenols, amino acids, vitamins and minerals (Original XPC'm, Diamond V, IOWA, USA) added to a commercially available dry cat food. Apparent digestibility of dietary nutrients, fecal microbiota, fecal fermentation products and immunological parameters were evaluated. Twenty-seven healthy cats of mixed sexes, with a mean body weight of $4.19 \pm 0.83 \mathrm{~kg}$ and a mean age of $9.44 \pm 5.35$ years were distributed by age in an unbalanced randomized block design, consisting of three experimental treatments: CD (control diet), YAM 0.3 (control diet with $0.3 \%$ yeast with active metabolites) and YAM 0.6 (control diet with $0.6 \%$ yeast with active metabolites).
\end{abstract}

Results: The inclusion of the additive elevated the apparent digestibility of crude fiber $(p=0.013)$ and ash $(p<0.001)$ without interfering feed consumption, fecal production and fecal characteristics. Regarding fermentation products present in the feces, prebiotic inclusion increased lactic acid concentration $(p=0.004)$ while reducing isovaleric acid $(p=0.014)$, only in the treatment YAM 0.3. No differences were noticed on biogenic amines (BA), fecal pH, ammonia concentration, total and individuals short-chain fatty acids (SCFA) and total and individuals branched-chain fatty acids (BCFA) (except isovaleric acid in YAM 0.3). As regards to fecal microbiota, prebiotic inclusion has resulted in the reduction of Clostridium perfringens ( $p=0.023$ ). No differences were found in the immunological parameters evaluated.

Conclusion: It can be concluded that the additive, at the levels of inclusion assessed shows prebiotic potential and it has effects on fecal fermentation products and microbiota without interfering on crude protein and dry matter digestibility. More studies evaluating grater inclusion levels of the prebiotic are necessary to determine optimal concentration.

Keywords: Biogenic amines, Fecal real-time PCR, Feline, Fermentation, Isovaleric acid

*Correspondence: mabrunetto@usp.br

1 School of Veterinary Medicine and Animal Science, University of São Paulo, 87, Prof. Orlando Marques de Paiva Ave, São Paulo, São Paulo 05508270, Brazil

Full list of author information is available at the end of the article

\section{Background}

The intestinal microbiota provides the host various functions regarding physiology, especially related to metabolic and immune homeostasis [1]. Several factors can 
affect the intestinal microbiota, but the diet plays this role predominantly $[2,3]$. It is known that dysbiosis may be associated with some disorders, such as colorectal cancer, obesity, insulin resistance, type 2 diabetes mellitus, allergic diseases, among others $[4,5]$ and the use of nutraceuticals can prevent it through gut microbiota modulation [6].

Nutraceuticals are substances that have the ability to improve animal health and have been increasingly studied in pet nutrition $[7,8]$. An example of nutraceutical are prebiotics that can be defined as a non-digestible food ingredient that beneficially affects the host by selectively stimulating growth and/or activity of a limited number of bacteria in the colon $[1,6,9-11]$. In this context of food promoting health, prebiotics have been the subject of numerous scientific studies and there are publications which have demonstrated their therapeutic effectiveness on both systemic and gastrointestinal tract [11-16].

The Saccharomyces cerevisiae cell wall is a prebiotic composed of two fractions: one formed by beta-glucans and chitin and the other consisting of mannoproteins such as mannan oligosaccharides (MOS) [17]. When this yeast is dehydrated it becomes a commercial product called: Original XPC ${ }^{\mathrm{tm}}$ (Diamond V., Iowa, USA), which is intended for feeding several species of domestic animals, such as cats. The recommendation of this product for cats is $2 \mathrm{~kg} / \mathrm{ton}$. This yeast with active metabolites (YAM) has a final composition of beta glucans, nucleotides, organic acids, polyphenols, amino acids, vitamins and minerals.

Considering the potential benefits of modulating intestinal microbiota and the likely prebiotic action of YAM, the objective of this experiment was to evaluate the effect of supplementing increasing levels of YAM on fecal microbiota, fecal fermentation products, digestibility, and immunological parameters of healthy adult cats.

\section{Results}

During the study, two animals of CD and one of YAM 0.3 were excluded for not ingesting an adequate amount of food. At the end of the study, the number of animals per group was: eight of CD, nine of YAM 0.3 and ten of YAM 0.6 .

Feed intake was adequate, and the animals have ingested the amount of feed proposed by NRC [18] to achieve the maintenance energy requirement. All cats maintained constant body weight (BW) during the experiment $(4.29 \pm 0.89 \mathrm{~kg})$. The mean $\mathrm{BW}$ of the $\mathrm{CD}$ was $3.9 \pm 0.89 \mathrm{~kg}$; YAM 0.3 was $3.97 \pm 0.54 \mathrm{~kg}$ and YAM 0.6 was $4.52 \pm 0.90 \mathrm{~kg}$. The animals did not present a significant difference in BW among treatments.

The results of the nutrient intake (g/day), fecal production (g/dry matter/day), fecal score and apparent nutrient digestibility (\%) are described in Table 1 . There was no difference in the average daily intake of dry matter $(\mathrm{DM})$, organic matter $(\mathrm{OM})$ or nutrients by the animals. Fecal production and fecal scores also did not differ. The inclusion of the prebiotic did not influence the apparent nutrient digestibility of $\mathrm{DM}, \mathrm{OM}$, crude protein (CP), acid-hydrolyzed fat (AHF), or nitrogen-free extract (NFE). For crude fiber (CF), higher digestibility was observed in the yeast-treated groups than in the $\mathrm{CD}$ $(p=0.013)$, similar results were observed for ash, meantime YAM 0.6 superior to YAM $0.3(p<0.001)$. In relation to gross energy (GE) $(p=0.033)$ from the diets, the $\mathrm{CD}$ was superior to the supplemented groups.

There was no difference in fecal $\mathrm{pH}$ or concentration of ammonia, acetic, propionic, or butyric acid, total SCFA, valeric, isobutyric acid or total BCFA (Table 2). Lactic acid concentration $(p=0.004)$ was lower in the $C D$ and YAM 3.0 had a lower concentration of the isovaleric acid comparing to other treatments $(p=0.014)$ (Table 2).

There was no difference between groups in the fecal concentration of cadaverine, spermidine, histamine, putrescine, tyramine or total BA (Table 3). The BA: agmatine, phenylethylamine, serotonin, and tryptamine were analyzed, but these compounds were not found in the feces of any group.

There was no difference in the abundance of the bacterial genera Bifidobacterium or Lactobacillus or in the combined abundance of E. coli, H. alvei and Shigella spp. (Table 4). The species C. perfringens $(p=0.023)$ showed a reduction in abundance with yeast inclusion (Table 4).

There was no difference between groups in CD4+ or CD8+ lymphocytes, CD4+/CD8+ ratio, basal or induced oxidative bursts, phagocytosis index or the proliferative response of lymphocytes to the mitogens concanavalin A (ConA) and phytohemagglutinin (PHA) (Table 5).

\section{Discussion}

In this study the effect of increasing levels $(0,0.3$ and $0.6 \%$ ) of a commercial Saccharomyces cerevisiae cell wall product on consumption, apparent digestibility of nutrients, fecal characteristics, fermentation products, fecal BA, fecal microbiota and immunological parameters of cats were evaluated.

In previous studies of yeast cell wall (YCW) as a feed additive for dogs and cats, no difference in DM intake was observed between treatments [15, 19-22]. In relation to fecal production the same lack of difference was observed in dogs with the inclusion of the prebiotic MOS, which is also present in YAM composition $[11,12$, 23]. Theodoro et al. [22] observed that the MOS fraction from YCW can modulate dogs intestinal microbiota. 
Table 1 Nutrient intake, fecal production, fecal score and apparent nutrient digestibility in cats fed with increasing levels of YAM

\begin{tabular}{|c|c|c|c|c|c|c|c|}
\hline \multirow[b]{2}{*}{ Item } & \multicolumn{6}{|l|}{ Diets $^{\dagger}$} & \multirow[b]{2}{*}{$p$-value } \\
\hline & $\overline{C D}$ & SEM $^{\ddagger}$ & YAM 0.3 & SEM $^{\ddagger}$ & YAM 0.6 & SEM $^{\ddagger}$ & \\
\hline \multicolumn{8}{|l|}{ Intake, g/day } \\
\hline Dry matter & 60.33 & 6.65 & 61.07 & 4.53 & 55.89 & 3.43 & 0.727 \\
\hline Organic matter & 60.09 & 7.08 & 62.82 & 4.59 & 57.20 & 3.51 & 0.732 \\
\hline Crude protein & 20.81 & 2.45 & 20.24 & 1.48 & 18.58 & 1.14 & 0.617 \\
\hline Acid-hydrolyzed fat & 8.53 & 1.07 & 10.77 & 0.78 & 8.97 & 0.55 & 0.160 \\
\hline Crude fiber & 1.13 & 0.14 & 1.48 & 0.10 & 1.41 & 0.08 & 0.109 \\
\hline Ash & 3.67 & 0.46 & 4.67 & 0.34 & 4.55 & 0.24 & 0.187 \\
\hline Nitrogen-free extract & 25.20 & 2.97 & 24.56 & 1.79 & 22.90 & 1.40 & 0.707 \\
\hline \multicolumn{8}{|l|}{ Fecal production } \\
\hline Fecal production, g/DM/d & 7.22 & 1.01 & 9.10 & 0.74 & 7.87 & 0.44 & 0.808 \\
\hline Fecal score & 4.41 & 0.24 & 4.67 & 0.15 & 4.55 & 0.24 & 0.628 \\
\hline \multicolumn{8}{|c|}{ Apparent nutrient digestibility, \% } \\
\hline Dry matter & 84.04 & 1.16 & 84.92 & 0.94 & 85.78 & 0.68 & 0.394 \\
\hline Organic matter & 87.38 & 0.93 & 87.82 & 0.95 & 87.82 & 0.71 & 0.677 \\
\hline Crude protein & 87.42 & 1.22 & 88.35 & 1.25 & 87.60 & 0.99 & 0.631 \\
\hline Acid-hydrolyzed fat & 93.99 & 1.63 & 95.21 & 0.89 & 95.21 & 0.68 & 0.354 \\
\hline Crude fiber & $14.60^{\mathrm{a}}$ & 3.56 & $27.11^{\mathrm{b}}$ & 3.85 & $33.79^{b}$ & 4.25 & 0.013 \\
\hline Ash & $43.28^{\mathrm{a}}$ & 2.85 & $50.10^{b}$ & 1.12 & $53.55^{c}$ & 1.09 & $<0.001$ \\
\hline Nitrogen-free extract & 89.62 & 1.01 & 88.58 & 0.91 & 89.80 & 0.78 & 0.597 \\
\hline Gross energy, kcal/g & $3.99^{\mathrm{a}}$ & 0.05 & $3.82^{\mathrm{ab}}$ & 0.05 & $3.71^{b}$ & 0.04 & 0.033 \\
\hline
\end{tabular}

$a, b, c$ Values in the same row with different superscripts differ significantly

${ }^{\dagger}$ Diets: CD (control diet); YAM 0.3 (control diet containing $0.3 \%$ yeast with active metabolites); YAM 0.6 (control diet containing $0.6 \%$ yeast with active metabolites)

${ }^{\ddagger}$ SEM standard error of the mean

Table 2 Fecal pH, fecal concentration of lactic acid, ammonia, short-chain fatty acids, and branched-chain fatty acids of cats fed with increasing levels of YAM

\begin{tabular}{|c|c|c|c|c|c|c|c|}
\hline \multirow[b]{2}{*}{ Item } & \multicolumn{6}{|l|}{ Diets $^{c}$} & \multirow[b]{2}{*}{$p$-value } \\
\hline & $\overline{C D}$ & SEM $^{d}$ & YAM 0.3 & SEM $^{d}$ & YAM 0.6 & SEM $^{\mathrm{d}}$ & \\
\hline $\mathrm{pH}$ & 6.00 & 0.14 & 5.94 & 0.12 & 6.08 & 0.11 & 0.756 \\
\hline Lactic acid, $\mu \mathrm{mol} / \mathrm{kg}$ of DM & $1.36^{\mathrm{a}}$ & 0.34 & $3.42^{b}$ & 0.84 & $4.24^{\mathrm{b}}$ & 1.01 & 0.004 \\
\hline Ammonia, $\mu \mathrm{mol} / \mathrm{kg}$ of $\mathrm{DM}$ & 140.26 & 21.87 & 133.75 & 10.85 & 163.33 & 12.76 & 0.286 \\
\hline \multicolumn{8}{|l|}{ Short-chain fatty acids, $\mu \mathrm{mol} / \mathrm{kg}$ of DM } \\
\hline Acetic acid & 66.82 & 11.49 & 92.92 & 12.80 & 66.59 & 10.15 & 0.216 \\
\hline Propionic acid & 32.47 & 6.19 & 27.08 & 4.37 & 30.38 & 5.23 & 0.782 \\
\hline Butyric acid & 24.50 & 7.41 & 40.29 & 12.30 & 24.84 & 5.69 & 0.545 \\
\hline Total short-chain fatty acids & 123.79 & 22.26 & 160.29 & 21.05 & 121.81 & 14.57 & 0.329 \\
\hline \multicolumn{8}{|c|}{ Branched-chain fatty acids, $\mu \mathrm{mol} / \mathrm{kg}$ of DM } \\
\hline Valeric acid & 9.86 & 2.67 & 14.40 & 2.70 & 12.63 & 2.79 & 0.514 \\
\hline Isobutyric acid & 2.31 & 0.32 & 2.30 & 0.41 & 2.71 & 0.34 & 0.694 \\
\hline Isovaleric acid & $2.39^{b}$ & 0.50 & $1.85^{\mathrm{a}}$ & 0.25 & $2.98^{b}$ & 0.47 & 0.014 \\
\hline Total branched-chain fatty acids & 15.10 & 3.35 & 17.06 & 2.99 & 16.50 & 3.08 & 0.673 \\
\hline
\end{tabular}

a-b Values in the same row with different superscripts differ significantly

${ }^{c}$ Diets: CD (control diet); YAM 0.3 (control diet containing $0.3 \%$ yeast with active metabolites); YAM 0.6 (control diet containing $0.6 \%$ yeast with active metabolites)

d SEM standard error of the mean 
Table 3 Biogenic amines concentrations ( $\mu \mathrm{mol} / \mathrm{kg}$ of DM) in the feces of cats fed with increasing levels of YAM

\begin{tabular}{|c|c|c|c|c|c|c|c|}
\hline \multirow[b]{2}{*}{ Item } & \multicolumn{6}{|c|}{ Diets $^{a}$} & \multirow[b]{2}{*}{$p$-value } \\
\hline & $\mathrm{CD}$ & SEM $^{b}$ & YAM 0.3 & SEM $^{b}$ & YAM 0.6 & $\mathrm{SEM}^{\mathrm{b}}$ & \\
\hline Cadaverine & 10.47 & 1.54 & 9.14 & 1.20 & 11.99 & 2.09 & 0.481 \\
\hline Spermidine & 0.45 & 0.10 & 0.32 & 0.05 & 0.55 & 0.08 & 0.145 \\
\hline Histamine & 1.57 & 0.45 & 1.24 & 0.33 & 1.25 & 0.33 & 0.711 \\
\hline Putrescine & 4.75 & 1.13 & 4.72 & 0.73 & 6.07 & 1.47 & 0.603 \\
\hline Tyramine & 3.81 & 0.82 & 4.97 & 0.89 & 5.70 & 1.18 & 0.464 \\
\hline Total biogenic amines & 21.03 & 2.89 & 20.41 & 2.63 & 25.56 & 4.48 & 0.519 \\
\hline
\end{tabular}

${ }^{a}$ Diets: CD (control diet); YAM 0.3 (control diet containing $0.3 \%$ yeast with active metabolites); YAM 0.6 (control diet containing $0.6 \%$ yeast with active metabolites)

${ }^{\mathrm{b}}$ SEM standard error of the mean

Table 4 Quantification of fecal bacteria by quantitative real-time PCR (log10 cfu/g of faecal DM) in cats fed with increasing levels of YAM

\begin{tabular}{|c|c|c|c|c|c|c|c|}
\hline \multirow[b]{2}{*}{ Item } & \multicolumn{6}{|c|}{ Diets $^{c}$} & \multirow[b]{2}{*}{$p$-value } \\
\hline & $C D$ & SEM $^{d}$ & YAM 0.3 & SEM $^{d}$ & YAM 0.6 & SEM $^{d}$ & \\
\hline Bifidobacterium spp. & 1.00 & - & 1.62 & 2.33 & 0.89 & 1.60 & 0.883 \\
\hline Lactobacillus spp. & 1.00 & - & 0.62 & 0.98 & 0.52 & 1.02 & 0.376 \\
\hline Clostridium perfringens & $1.00^{b}$ & - & $0.10^{\mathrm{a}}$ & 0.13 & $0.10^{\mathrm{a}}$ & 0.06 & 0.023 \\
\hline E. coli - Hafnia alvei - Shigella spp. & 1.00 & - & 0.70 & 1.09 & 0.40 & 1.01 & 0.420 \\
\hline
\end{tabular}

${ }^{\mathrm{a}-\mathrm{b}}$ Values in the same row with different superscripts differ significantly

' Diets: CD (control diet); YAM 0.3 (control diet containing $0.3 \%$ yeast with active metabolites); YAM 0.6 (control diet containing $0.6 \%$ yeast with active metabolites)

d SEM standard error of the mean

Table 5 Lymphocyte immunophenotyping, phagocytosis test, oxidative burst and lymphoproliferation test of cats fed with increasing levels of YAM

\begin{tabular}{|c|c|c|c|c|c|c|c|}
\hline \multirow[b]{2}{*}{ Item } & \multirow[b]{2}{*}{$C D$} & \multirow[b]{2}{*}{ SEM $^{b}$} & \multicolumn{3}{|l|}{ Diets $^{\mathrm{a}}$} & \multirow[b]{2}{*}{ SEM $^{b}$} & \multirow[b]{2}{*}{$p$-value } \\
\hline & & & YAM 0.3 & SEM $^{b}$ & YAM 0.6 & & \\
\hline $\mathrm{CD}^{+}$(T helper cells), \% & 24.76 & 2.56 & 28.85 & 2.60 & 26.44 & 3.12 & 0.261 \\
\hline $\mathrm{CD}^{+}$(cytotoxic T cells), \% & 11.34 & 1.99 & 10.67 & 1.68 & 11.58 & 1.40 & 0.931 \\
\hline $\mathrm{CD}^{+} / \mathrm{CD}^{+}$ratio & 2.67 & 0.44 & 3.27 & 0.55 & 2.30 & 0.30 & 0.260 \\
\hline Basal oxidative burst $^{c}$ & 255.63 & 18.26 & 211.00 & 27.62 & 256.29 & 35.92 & 0.372 \\
\hline Induced oxidative burst ${ }^{c}$ & 1686.38 & 225.72 & 1754.00 & 272.30 & 1597.63 & 418.82 & 0.947 \\
\hline Phagocytosis index ${ }^{c}$ & 253.67 & 41.51 & 186.44 & 69.85 & 245.55 & 73.11 & 0.733 \\
\hline Concanavalin $A^{c}$ & 234.88 & 16.02 & 228.36 & 8.81 & 236.71 & 14.00 & 0.917 \\
\hline Phytohemagglutinin ${ }^{c}$ & 660.75 & 21.64 & 608.11 & 36.82 & 583.50 & 36.03 & 0.264 \\
\hline
\end{tabular}

${ }^{\text {a }} \mathrm{CD}$ (control diet); YAM 0.3 (control diet containing $0.3 \%$ yeast with active metabolites); YAM 0.6 (control diet containing $0.6 \%$ yeast with active metabolites)

b SEM: standard error of the mean

'Values was expressed as arbitrary units of fluorescence

The high CF digestibility of the diets containing YAM need to be considered with caution. Probably these may have occurred by calculation errors, as all diets had low fiber concentrations and, consequently small differences between fiber digestibility in basal and test diets could result in calculation errors [24]. Besides, de-Oliveira et al. [25] hypothesized that some fiber compounds can become more soluble because of microbial degradation and will not be measured in the CF analysis. For this reason, a smaller content of CF may have been identified in stool which was interpreted as a higher digestibility.

Regarding ash digestibility, a previous study evaluating the effects of dietary supplementation in cats with spray dried Saccharomyces cerevisiae cell wall verified 
an increase in this parameter [15], which corroborates our study. This effect may be caused due to an increase in bacterial content and their fermentation metabolites. For example, some bacteria can produce phytase enzyme, which can release minerals attached to phytate increasing their availability. Another example is the induction of the bioactive peptides production by some bacterial groups which also may induce greater availability of minerals [26].

In relation to GE, according to NRC [18] it is defined as the total chemical energy arising from complete combustion of a food in a calorimeter bomb. Different nutrients have different ranges of GE reported and among all nutrients the carbohydrates (including fibers) have the smaller GE content [18]. In this study the diets containing YAM addition had smaller GE than the $\mathrm{CD}$ which was expected since they have greater fiber content.

With the addition of YAM, it would be expected a reduction on fecal $\mathrm{pH}$ caused by gut microbiota fermentation, as it was observed by Middelbos et al. [19] using YCW in dogs' diet. On the other hand, Lin et al. [21] and Theodoro et al. [22] did not observed fecal $\mathrm{pH}$ alteration with the addition of YCW for dogs and Santos et al. [15] also did not observed this alteration for cats. The authors believe that the level of YCW inclusion may not have been sufficient in these dosages to cause an alteration on this parameter, which can also have happened in our study.

The short chain fatty acids are the main end-products of the bacterial fermentation in the mammal's colon, and they are considered as indicators of nutritional evaluation of ingredients rich in carbohydrates used in petfood [27]. The main SCFA are rapidly absorbed and then metabolized by the gut epithelium, liver and muscle, and have a trophic effect on the intestinal epithelium, maintaining the mucosal defense barrier against pathogens organisms [28].

Alterations in SCFA may influence on fecal pH [29], and as for fecal $\mathrm{pH}$, no differences were found on total SCFA or acetic, propionic and butyric acids. Considering SCFA, our results corroborate those presented by Santos et al. [15] that did not found difference between treated and untreated cats. However, other authors found an increase in SCFAs (acetate and total SCFA) when dogs were fed a beef-based diet with $1.4 \%$ YCW extract [30] or when cats consumed a combination of fructooligosaccharides (FOS) and galactooligosaccharides (GOS) or GOS and Bifidobacterium pseudocatenulatum as $0.5 \%$ of their diet [14]. Therefore, a higher inclusion of YAM or a combination of probiotics and prebiotics may be able to increase SCFAs. However, more studies are necessary to support this hypothesis.
Non digested nitrogenous compounds can be metabolized in the gut and produce putrefactive catabolites such as ammonia, BA and phenols [31]. As regards to ammonia it can contribute to colon carcinogenesis and also reduction in the height of intestinal villi $[31,32]$. In the present study, the fecal concentration of ammonia was not affected by the inclusion of the prebiotic. Previous studies corroborate this finding, as the dietary inclusion of FOS and MOS did not affect the ammonia concentration in dog's feces [11, 12, 23]. Theodoro et al. [22] also find no difference in the fecal ammonia production of dogs after eating diets with the addition of YCW. Regarding the gut fermentation profile, bacteria use $\mathrm{N}$ (specially ammonia) to synthesis of bacterial mass [33]. Carbohydrates (as prebiotics) can serve as energy source to fermentation and bacterial growth [6]. This process results in the decrease of luminal concentration of nitrogenous compounds and increase in fecal $\mathrm{N}$ (comprised by bacterial mass) concentration [34]. Higher doses of YAM may be required to imply on decreases in the concentrations of BCFA and BA measured in feces, considering that those compounds are formed by nitrogen compounds fermentation.

In contradiction to the abovementioned regarding $\mathrm{BA}$, there are other studies in the literature indicating its increase with prebiotic addition [15]. According to the authors, as the gut microbiota of cats is mainly comprehended by proteolytic bacteria and they cause substrate modulation. Moreover, Santos et al. [15] argument that saccharolytic bacteria growth may not be sufficient to reduce proteolytic microbes through competition. Considering these different effects in BA concentration found in the literature caused by prebiotics addition it is important that more studies are developed in this regard. Despite the effect expected, the concentration of YAM found in this study was not sufficient to cause any impact in fecal BA in cats.

This study could only identify as a result of gut fermentation indicating prebiotic effect the increase in lactic acid production and the reduction of isovaleric acid with the inclusion of the additive, probably because of the low inclusion levels. Regarding isovaleric acid, the addition of $0.3 \%$ YAM decreased this BCFA showing that it could be altered with less substrate than the other acids. This reduction in isovaleric acid, which is a catabolic of proteolytic activity, was accompanied by a reduction in $C$. perfringens, which supports a theory of proteolytic bacterial modulation [35]. The increase in this BCFA with the highest supplementation of the prebiotic needs further investigation.

As regards to acid lactic, according to Gannan et al. [36] the mannoproteins found in YCW can be used to enhance lactic acid bacteria intestinal populations and 
control pathogens. It has also been observed in this study by the increase in lactic acid with the addition of YAM in both concentrations, 0.3 and $0.6 \%$, despite the potentially low concentration levels of inclusion. On the whole, these results are suggestive of a higher proliferation of lactic acid bacteria, which have been indicated as the main probiotic genera for healthy intestine of mammals [37].

Regarding fecal microbiota, this study has only evaluated a few bacterial taxa and the inclusion of YAM for cats resulted in the reduction of $C$. perfringens. The modulation of $C$. perfringens in the present study corroborates the results found by Santos et al. [15] in cats supplemented with increasing levels of YCW. According to Vernazza et al. [38] the prebiotic effect of YCW is mainly caused by the ability of MOS to attach to type A fimbriae of Salmonellae and Clostridiae avoiding the adhesion to enterocytes and reducing their concentration in gut microbiota, which can explain the reduction of C. perfringens in our study. Furthermore, the inclusion of YAM may have had other effects on gut microbiota that were not evaluated in this study, improving the multiplication of lactic acid producing bacteria and their adhesion to the mucosa.

The inclusion of YAM in cat's diet did not altered any of the immunological parameter analyzed in this study, which is not in accordance to the literature [19-22, 31, 39]. However, this effect may not have been found in the present study owing to difficulties in establishing optimal doses for the prebiotic effect.

\section{Conclusion}

Supplementation of $S$. cerevisiae at concentrations of 0.3 and $0.6 \%$ in cat's diet can impact positively the gut microbiota by reducing $C$. perfringens concentrations. As consequence of this modulation the concentration of lactic acid, a beneficial metabolite is increased. All these positive effects are acquired without interfering the digestibility of DM and CP, indicating that nutrient harnessing of the diet is preserved. The effects observed with the addition of this prebiotic are beneficial to cats, however, further studies are needed to ascertain whether the inclusion of a higher dose of this prebiotic can provide more pronounced effects on felines.

\section{Methods}

All procedures were approved by the Ethics Committee in the Use of Animals of the School of Veterinary Medicine and Animal Science of University of São Paulo, protocol number: 3283091014/2016.

\section{Experimental diets}

The diets followed the AAFCO [40] recommendation for adult cat maintenance. A control diet was formulated and used as a basis for two other diets: YAM 0.3 (the control diet supplemented with $0.3 \%$ YAM) and YAM 0.6 (the control diet supplemented with 0.6\% YAM) (Table 6). The animals were feeding three times a day with one of the three experimental extruded diets.

The amount of food offered to the cats was calculated by the National Research Council [18] equation for adult

Table 6 Ingredients and chemical composition of experimental diets

\begin{tabular}{|c|c|c|c|}
\hline \multirow[b]{2}{*}{ Item } & \multicolumn{3}{|l|}{ Diets $^{a}$} \\
\hline & $\overline{C D}$ & YAM 0.3 & YAM 0.6 \\
\hline \multicolumn{4}{|l|}{ Ingredients, g/kg dry matter } \\
\hline Corn starch & 10.0 & 7.0 & 4.0 \\
\hline Original XPC & - & 3.0 & 6.0 \\
\hline Corn & 453.5 & 453.5 & 453.5 \\
\hline Poultry by-product meal & 300.8 & 300.8 & 300.8 \\
\hline Corn gluten $60 \%$ & 93.9 & 93.9 & 93.9 \\
\hline Poultry fat & 92.1 & 92.1 & 92.1 \\
\hline Liquid flavor enhancer & 20.0 & 20.0 & 20.0 \\
\hline Powder flavor enhancer & 5.0 & 5.0 & 5.0 \\
\hline Potassium chloride & 4.3 & 4.3 & 4.3 \\
\hline Salt & 3.5 & 3.5 & 3.5 \\
\hline Calcium carbonate & 4.0 & 4.0 & 4.0 \\
\hline Vitamins and mineral premix ${ }^{b}$ & 5.0 & 5.0 & 5.0 \\
\hline Choline chloride 60\% & 4.0 & 4.0 & 4.0 \\
\hline Mold inhibitor & 2.0 & 2.0 & 2.0 \\
\hline Antioxidant $^{\S}$ & 0.4 & 0.4 & 0.4 \\
\hline Taurine & 1.5 & 1.5 & 1.5 \\
\hline \multicolumn{4}{|c|}{ Chemical composition, $\mathrm{g} / \mathrm{kg}$ dry matter } \\
\hline Dry matter, $\mathrm{g} / \mathrm{kg}$ as fed & 942.1 & 914.6 & 912.7 \\
\hline Crude protein & 345.0 & 328.0 & 332.4 \\
\hline Acid-hydrolyzed fat & 151.8 & 174.6 & 16.05 \\
\hline Crude fiber & 20.2 & 24.1 & 25.3 \\
\hline Ash & 65.4 & 75.3 & 72.1 \\
\hline Nitrogen-free extract & 417.7 & 398.0 & 409.7 \\
\hline Calcium & 11.3 & 13.9 & 13.0 \\
\hline Phosphorus & 11.3 & 11.2 & 10.8 \\
\hline Gross energy, kcal/kg & 4744 & 4567 & 4513 \\
\hline
\end{tabular}

${ }^{a} \mathrm{CD}$ (control diet); YAM 0.3 (control diet containing $0.3 \%$ yeast with active metabolites); YAM 0.6 (control diet containing $0.6 \%$ of yeasts with active metabolites)

Original XPC composition: crude protein - $15 \%$; crude fat - $1.5 \%$; crude fiber $25 \%$; ash $-9 \%$; moisture $11 \%$; arginine $-0.73 \%$; cystine - $0.33 \%$; glycine $-0.93 \%$. histidine - $0.44 \%$; isoleucine $-0.57 \%$; leucine $-1.03 \%$; lysine (total) $-0.87 \%$; methionine $-0.28 \%$; phenylalanine $-0.61 \%$; proline $-0.93 \%$; threonine $-0.60 \%$; tyrosine $0.55 \%$; tryptophan - $0.19 \%$; valine $-0.78 \%$; starch $-<10 \%$; ADF $24.68 \%$; NDF - 37.74 ; calcium $-0.56 \%$; chloride $-0.37 \%$; magnesium $-0.39 \%$; phosphorus $-0.54 \%$; potassium $-2.57 \%$; sodium - $0.09 \%$; sulphur $-0.46 \%$.

${ }^{\mathrm{b}}$ Supplements per kilogram of product: iron $100 \mathrm{mg}$; copper $10 \mathrm{mg}$; manganese $10 \mathrm{mg}$; zinc $150 \mathrm{mg}$; iodine $2 \mathrm{mg}$; selenium $0.3 \mathrm{mg}$; vitamin A $18000 \mathrm{IU}$; vitamin D $1200 \mathrm{IU}$; vitamin E $200 \mathrm{IU}$; thiamine $6 \mathrm{mg}$; riboflavin $10 \mathrm{mg}$; pantothenic acid $40 \mathrm{mg}$; niacin $60 \mathrm{mg}$; pyridoxine $6 \mathrm{mg}$; folic acid $0.30 \mathrm{mg}$; vitamin $B_{12} 0.1 \mathrm{mg}$. Antioxidants: BHA and BHT 
cats, as follows: $100 \mathrm{x}(\mathrm{BW})^{0.67}=\mathrm{kcal} /$ day. Regarding feed intake, all animals have ingested the proposed amount to maintain BW.

\section{Animals and experimental design}

The study was conducted at Premier Pet Nutritional Development Center, Dourado, Brazil, along with the Department of Animal Nutrition and Production at School of Veterinary Medicine and Animal Science, University of São Paulo, Pirassununga, Brazil.

Thirty healthy adult domestic cats of mixed sexes, ten per group, with a mean initial age of $9.44 \pm 5.35$ years and a mean initial BW of $4.19 \pm 0.83 \mathrm{~kg}$, were distributed in two unbalanced randomized blocks according to age (adult and senior). They were divided in blocks to eliminate the age influence over the evaluated parameters. Each group was composed of three animals younger than 5 years old and the remaining were older than 10 years old.

The study period consisted of 37 days, divided into four phases: I) food adaptation (days 1 to 21); II) fecal collection for digestibility and fecal score (days 22 to 29); III) fecal collection for microbiota and fermentation products (days 30 to 34); and IV) blood collection for immunological parameters (days 35 to 37 ).

Cats were individually housed in clean metabolic cages $(56 \times 58 \times 115 \mathrm{~cm})$ in a temperature-controlled room at the laboratory at Premier Pet for the collection of feces. The BW of the animals was controlled weekly.

\section{Digestibility and fecal score}

Digestibility was measured by total collection of feces without urine collection. The amount of food intake was recorded daily. The feces were stored in a freezer $\left(-15^{\circ} \mathrm{C}\right)$ and, at the end of the study period, were analyzed at the Multiuser Laboratory of Animal Nutrition and Bromatology of the Department of Animal Nutrition and Production at School of Veterinary Medicine and Animal Science, University of São Paulo, Pirassununga, Brazil.

Product samples were dehydrated in a forced ventilation chamber at $55^{\circ} \mathrm{C}$ for $72 \mathrm{~h}$, according to the method proposed by AOAC (2006) (method 930.15). The diets were ground in a grain mill with a $1 \mathrm{~mm}$ sieve, and DM was determined by oven drying at $105^{\circ} \mathrm{C}$. Nitrogen content was determined by the Kjeldahl method, and it was used to calculate CP. CF content was determined by the Weende method. AHF was determined by the traditional method, as specified by AOAC [41] (method 954.02), using a Soxhlet system with previous acid hydrolysis. Ash content was determined using the method proposed by AOAC [41] (method 942.05). The NFE were calculated using the formula: NFE $=100$
- (\% CP $+\% \mathrm{AHF}+\% \mathrm{CF}+\% \mathrm{ash})$. The $\mathrm{OM}$ was calculated using the formula: $\mathrm{MO}=100$ - \%ash.

The GE content of the diets, feces, and urine was determined in a bomb calorimeter (1281, PAAR Instrument Company, Illinois, USA) at the Animal Nutrition Laboratory of São Paulo State University, Jaboticabal, Brazil. All samples were analyzed in duplicate, and the analysis was repeated when the variation was more than $5 \%$.

During the fecal collection, fecal quality was scored on the following scale: 1 =watery: liquid that can be poured; $2=$ soft, unformed: stool assumes shape of container; $3=$ soft, formed, moist: softer stool that retains shape; $4=$ hard, formed, dry stool: remains firm and soft; $5=$ hard, dry pellets: small, hard mass [42].

\section{Fecal $\mathrm{pH}$, lactate, ammonia and fermentation products}

Feces were collected for $\mathrm{pH}$ and fermentation products up to $30 \mathrm{~min}$ after defecation. Fecal $\mathrm{pH}$ was measured by direct insertion of the probe of a $\mathrm{pH}$ meter (Digimed, DM-20, São Paulo, Brazil) into a solution of homogenized feces. A 9:1 solution of distilled water and feces was used, according to an adapted version of the method described by Walter et al. [43].

Lactic acid was measured by Pryce's colorimetric method [44] (Quick-Lab Spectrophotometer, Drake, São José do Rio Preto, Brazil) at the Multiuser Laboratory of Animal Nutrition and Bromatology of the Department of Animal Nutrition and Production at School of Veterinary Medicine and Animal Science, University of São Paulo, Pirassununga, Brazil.

Fecal ammonia was measured according to the method of Urrego et al. [45] using a Kjeldahl nitrogen system (TE Tecnal - 036/1, Piracicaba, Brazil).

The concentrations of SCFA and BCFA were analyzed by gas chromatography (model 9001, Finnigan, San Jose, USA) according to Erwin et al. [46] with a flame ionization detector (at a working temperature of $250^{\circ} \mathrm{C}$ ) controlled by the software GC solution from Shimadzu. The gas chromatograph was equipped with a capillary column (Stabilwax, Restek, Bellefonte, EUA) kept at $145^{\circ} \mathrm{C}$, and helium gas served as the carrier. For calibration, we used an external standard solution with acetic, propionic, butyric, valeric, isovaleric and isobutyric acids. The total concentration of SCFA value was obtained by the sum of concentrations of the acetic, propionic and butyric acids. The total concentration of BCFA value was obtained by the sum of concentrations of the valeric, isovaleric and isobutyric acids.

\section{Biogenic amines}

This analysis was performed in the Laboratory of Food Biochemistry in the Food Department at the Faculty of Pharmacy of University of Minas Gerais, Belo Horizonte, 
Brazil. Briefly, after feces collection, $0.5 \mathrm{~g}$ of fresh feces was collected and preserved chilled in trichloroacetic acid $(5 \mathrm{~g} / 100 \mathrm{~mL})$. The samples were centrifuged 3 times at $10,000 \times \mathrm{g}$ for $20 \mathrm{~min}$ at $4^{\circ} \mathrm{C}$, after which the supernatant was removed and analyzed by high-performance liquid chromatography [47].

\section{Fecal microbiota}

Quantification of fecal microbiota was performed in the Laboratory of Functional Genomics in the Department of Animal Nutrition and Production at School of Veterinary Medicine and Animal Science, University of São Paulo, Pirassununga, Brazil.

. The detection of Lactobacillus spp. [48], Bifidobacterium spp. [49], Clostridium perfringens [50] and E. coli, Hafnia alvei and Shigella spp. [51] were determined by real-time PCR. For the DNA extraction, a commercial kit was utilized (QIAamp).

Centrifugation cycles were analyzed in NetPrimer to check the optimal conditions for amplification, and specificity was checked by Basic Local Alignment Search Tool (BLAST) software (National Center for Biotechnology Information - NCBI), with the amplification performed in a Rotor Gene 6000 thermocycler (Corbett Life Science, Hilden, Düsseldorf, Germany).

Amplification reactions were performed in duplicate, and the final volume of $20 \mu \mathrm{L}$ consisted of $10 \mu \mathrm{L}$ of Master Mix SYBR Green (Promega, São Paulo, Brazil), $30.45 \mu \mathrm{L}$ of forward primer $(100 \mu \mathrm{M}), 0.45 \mu \mathrm{L}$ of reverse primer $(100 \mu \mathrm{M})$, and $2 \mathrm{~nL}$ of DNA. Water was used as a negative control in each amplification reaction. The thermocycler was programmed to hold at $95^{\circ} \mathrm{C}$ for $10 \mathrm{~min}$ for all amplification reactions.

\section{Immunological tests}

All immunological tests (phagocytosis test and oxidative burst in neutrophils, lymphocyte proliferation assay and immunophenotypic) were performed in the Applied Pharmacology and Toxicology Laboratory of the Pathology Department in the School of Veterinary Medicine and Animal Science of the University of Sao Paulo.

\section{Phagocytosis test and the oxidative burst test}

Blood leukocytes (lymphocytes, neutrophils, and monocytes) were incubated with a fluorescent reagent indicating the production of reactive oxygen species; this reagent was applied in the basal state and after phagocytosis of Streptococcus aureus bacteria to indicate the percentage and intensity of phagocytosis. Cells were incubated with the reagent dichlorofluorescein diacetate (DCFH-DA) in phosphate-buffered saline (PBS) and maintained at $37{ }^{\circ} \mathrm{C}$ for $20 \mathrm{~min}$. DCFH-DA is a nonfluorescent cell-permeable dye that becomes fluorescent upon oxidation [52]. After the incubation period, the red blood cells were disrupted with a lysis solution, and the samples were washed with PBS until they appeared clear. The samples were then read on a FACSCalibur.

\section{Blood lymphocyte collection}

The total peripheral blood was diluted in PBS at a 1:1 ratio, carefully transferred to Ficoll solution with a density of $1077 \mathrm{~g} / \mathrm{dL}$ (GE Healthcare, Amersham, USA) at a 2:1 ratio and centrifuged continuously at $400 \times \mathrm{g}$ for $20 \mathrm{~min}$ at $23^{\circ} \mathrm{C}$ to separate the mononuclear cells. After centrifugation, the mononuclear cells were collected from the interface (between the plasma and the Ficoll) and washed twice by dilution in $10 \mathrm{~mL}$ of PBS and centrifugation at $300 \times \mathrm{g}$ for $5 \mathrm{~min}$ at $4^{\circ} \mathrm{C}$. The leukocyte pellet was resuspended in $1 \mathrm{~mL}$ of RPMI medium (Gibco), and a $10 \mu \mathrm{L}$ aliquot was withdrawn to count viable cells. Ten microliters of Trypan blue were added to this aliquot, and the cells were counted in a Neubauer chamber to allow adjustment of the number of cells in each assay.

\section{Lymphocyte proliferation assay}

The blood lymphocytes were labeled with carboxyfluorescein diacetate succinimidyl ester (CFSE) and seeded in triplicate at a concentration of $5 \times 10^{4}$ cells/well in 96-well U-bottom plates with or without ConA $(5 \mu \mathrm{g} / \mathrm{mL})$ and PHA $(10 \mu \mathrm{g} / \mathrm{mL})$, which are substances with mitogenic potential in $\mathrm{T}$ lymphocytes. The plates were incubated in a $5 \% \mathrm{CO}_{2}$ incubator at $40^{\circ} \mathrm{C}$ for $48 \mathrm{~h}$. CFSE binds covalently to intracellular molecules through carboxyfluorescein, a fluorescent dye. Therefore, when a CFSE labeled cell divides, each of its daughter cells carries half the number of molecules labeled with carboxyfluorescein; thus, the number of cell divisions can be evaluated by measuring the corresponding decrease in cell fluorescence by flow cytometry. The entry of the dye into the cell is possible because it is in its diacetylated form [carboxyfluorescein diacetate (CFDA), SE]. The acetate makes the dye highly membrane permeant, allowing its rapid flow into the cell. The esterases present in the cell cleave CFDA acetates, yielding CFSE, which is much less membrane permeant and consequently becomes concentrated in the cellular interior (Quah and Parish, 2010). At the end of three days, the cells were examined by flow cytometry (FACSCalibur) and analyzed by FlowJo.

\section{Immunophenotypic quantification}

Flow cytometric analysis was used to perform immunophenotyping to quantify $\mathrm{T}$ helper cells (CD4+), cytotoxic $\mathrm{T}$ cells (CD8+), and the CD4/CD8 ratio. Mononuclear cells $(2 \times 105$ cells $/ \mathrm{mL})$ were incubated in microtubes $(1.5 \mathrm{~mL})$ with anti-CD4 (1:10) and antiCD8 [(1:20) antibodies (Serotec, BioLegend, San Diego, 
USA), diluted in $100 \mu \mathrm{L}$ of cytometry buffer (PBS containing $0.5 \%$ bovine serum albumin and $0.02 \%$ sodium azide)], and then washed with buffer. We used gating criteria to identify a population of lymphocytes with low size and low complexity. Immunolabelling was performed according to the method of Gil et al. [53]. We analyzed 10.000 cells by flow cytometry.

\section{Statistical analysis}

Data were analyzed by the statistical software SAS (version 9.2, SAS Institute Inc., Cary, USA); the normality of errors was verified by the Shapiro-Wilk test (PROC UNIVARIATE), after which the variances were compared by the F-test. Variables that did not meet the assumptions were transformed with a log or square root transformation and were analyzed by PROC GLM in SAS by simple polynomial regression. To determine differences between treatments, we applied the method of least-square means using Tukey's test. Values of $p<0.05$ were considered significant.

\begin{abstract}
Abbreviations
YAM: Yeast with active metabolites; CD: Control diet; YAM 0.3: Control diet with $0.3 \%$ yeast with active metabolites; YAM 0.6: Control diet with $0.6 \%$ yeast with active metabolites; BA: Biogenic amines; SCFA: Short-chain fatty acids; BCFA: Branched-chain fatty acids; MOS: Mannan oligosaccharides; BW: Body weight; DM: Dry matter; OM: Organic matter; CP: Crude protein; AHF: Acidhydrolyzed fat; NFE: Nitrogen-free extract; CF: Crude fiber; GE: Gross energy; ConA: Concanavalin A; PHA: Phytohemagglutinin; YCW: Yeast cell wall; FOS: Fructooligosaccharides; GOS: Galactooligosaccharides; DCFH-DA: Reagent dichlorofluorescein diacetate; CFSE: Carboxyfluorescein diacetate succinimidyl ester; CFDA: Carboxyfluorescein diacetate.
\end{abstract}

\section{Acknowledgements}

We would like to thank the staff of the School of Veterinary Medicine and Animal Science for all their support, and Grandfood Industria e Comercio LTDA (Premier pet) for the maintenance of the Pet Nutrology Research Center. The first author acknowledges the scholarship granted by FAPESP - Fundação de Amparo à Pesquisa do Estado de São Paulo (process 2015/03994-2).

\section{Authors' contributions}

LFOM, MCE, JMS, PMO and COMSG were responsible for conducting the analysis, selecting, and treating animals, compiling the data. LWR, THAV, VP, $\angle B F H$ and $M A B$ were responsible for writing and editing the manuscript. MAB and CFFP were responsible for planning the study and manufacturing the diets. MAB were responsible for planning study and reviewing the manuscript. All authors have read and approved the manuscript.

\section{Funding}

This study was supported by Grandfood Industria e Comercio LTDA (Premier pet). The first author had scholarship granted by FAPESP - Fundação de Amparo à Pesquisa do Estado de São Paulo (process 2015/03994-2). Grandfood Industria e Comercio LTDA and FAPESP had no role in the analysis of results. Grandfood Industria e Comercio LTDA participated at study design and producing diets.

\section{Availability of data and materials}

All data generated or analyzed during this study are included in this published article.

\section{Declarations}

\section{Ethics approval and consent to participate}

The authors confirm that the ethical policies of the journal, as noted on the journal's author guidelines page, have been adhered to and the appropriate ethical review committee approval has been received. The authors confirm that they have followed EU standards for the protection of animals used for scientific purposes. All procedures were approved by the Ethics Committee of the Use of Animals of the School of Veterinary Medicine and Animal Science of University of São Paulo (protocol number: 3283091014/2016); and all procedures were performed with the dog owners' informed consent. Authors ensured that our manuscript conforms to the 'ARRIVE Guidelines for Reporting Animal Research'summarized at www.nc3rs.org.uk.

\section{Consent for publication}

Not applicable.

\section{Competing interests}

CFFP are employed in Grandfood Industria e Comercio LTDA (Premier pet). Grandfood Industria e Comercio LTDA had no role in the analysis of results and participated at study design and producing diets. Other/rest of the authors do not have any competing interest to declare.

\section{Author details}

${ }^{1}$ School of Veterinary Medicine and Animal Science, University of São Paulo, 87, Prof. Orlando Marques de Paiva Ave, São Paulo, São Paulo 05508270, Brazil. ${ }^{2}$ Department of Animal Sciences, University of Illinois at Urbana-Champaign, 120, 7 W Gregory Dr, Urbana, IL 61801, USA. ${ }^{3}$ Grandfood Industria e Comercio LTDA (Premier Pet, Luiz Augusto de Oliveira Hwy, km 204, Dourado, São Paulo 13590-000, Brazil.

Received: 9 April 2021 Accepted: 26 September 2021

Published online: 16 November 2021

\section{References}

1. Roberfroid M, Gibson GR, Hoyles L, McCartney AL, Rastall R, Rowland I, et al. Prebiotic effects: metabolic and health benefits. Br J Nutr. 2010;104:S1-63.

2. Suchodolski JS. Intestinal microbiota of dogs and cats: a bigger world than we thought. Vet Clin North Am - Small Anim Pract. 2011;41:261-72.

3. Lyu Y, Su C, Verbrugghe A, Van de Wiele T, Martinez-Caja AM, Hesta M. Past, present, and future of gastrointestinal microbiota research in cats. Front Microbiol. 2020;11.

4. Lynch SV, Pedersen O. The human intestinal microbiome in health and disease. N Engl J Med. 2016;375:2369-79.

5. Tizard IR, Jones SW. The microbiota regulates immunity and immunologic diseases in dogs and cats. Vet Clin North Am - Small Anim Pract. 2017:48:307-22.

6. Umu ÖCO, Rudi K, Diep DB. Modulation of the gut microbiota by prebiotic fibres and bacteriocins. Microb Ecol Health Dis. 2017;28:1348886.

7. AVMA. Manual D and R. American Veterinary Medical Association. Guidelines for alternative and complementary veterinary medicine. 48th edition. Illinois: American Veterinary Medical Association; 1999.

8. Zeisel SH. Regulation of "nutraceuticals." Science (80- ). 1999;285:1853-5.

9. Roberfroid M. Prebiotics: the concept revisited. J Nutr. 2007;137:830S-7S.

10. Gibson GR, Hutkins R, Sanders ME, Prescott SL, Reimer RA, Salminen SJ, et al. The international scientific Association for Probiotics and Prebiotics (ISAPP) consensus statement on the definition and scope of prebiotics. Nat Rev Gastroenterol Hepatol. 2017;14:491-502.

11. Rentas MF, Pedreira RS, Perini MP, Risolia LW, Zafalon RVA, Alvarenga IC, et al. Galactoligosaccharide and a prebiotic blend improve colonic health and immunity of adult dogs. PLoS One. 2020;15:e0238006.

12. Perini MP, Rentas MF, Pedreira R, Amaral AR, Zafalon RVA, Rodrigues RBA, et al. Duration of prebiotic intake is a key-factor for diet-induced modulation of immunity and fecal fermentation products in dogs. Microorganisms. 2020;8:1916.

13. Pinna C, Biagi G. The utilisation of prebiotics and synbiotics in dogs. Ital J Anim Sci. 2014;13:169-78. 
14. Kanakupt K, Vester Boler BM, Dunsford BR, Fahey GC. Effects of shortchain fructooligosaccharides and galactooligosaccharides, individually and in combination, on nutrient digestibility, fecal fermentative metabolite concentrations, and large bowel microbial ecology of healthy adults cats. J Anim Sci. 2011;89:1376-84.

15. Santos JPF, Aquino AA, Glória MBA, Avila-Campos MJ, Oba PM. Santos $K$ de $M$, et al. effects of dietary yeast cell wall on faecal bacteria and fermentation products in adult cats. J Anim Physiol Anim Nutr (Berl). 2018:102:1091-101.

16. Barry KA, Wojcicki BJ, Middelbos IS, Vester BM, Swanson KS, Fahey GC. Dietary cellulose, fructooligosaccharides, and pectin modify fecal protein catabolites and microbial populations in adult cats. J Anim Sci. 2010;88:2978-87.

17. Normand V, Dardelle G, Bouquerand PE, Nicolas L, Johnston DJ. Flavor encapsulation in yeasts: limonene used as a model system for characterization of the release mechanism. J Agric Food Chem. 2005;53:7532-43.

18. NRC - National Research Council. Nutrient Requirements of Dogs and Cats. Washington, DC: National Academies Press; 2006.

19. Middelbos IS, Godoy MR, Fastinger ND, Fahey GC. A dose-response evaluation of spray-dried yeast cell wall supplementation of diets fed to adult dogs: effects on nutrient digestibility, immune indices, and fecal microbial populations. J Anim Sci. 2007;85:3022-32.

20. Kroll FSA, Putarov TC, Zaine L, Venturini KS, Aoki CG, Santos JPF, et al. Active fractions of mannoproteins derived from yeast cell wall stimulate innate and acquired immunity of adult and elderly dogs. Anim Feed Sci Technol. 2020;261:114392.

21. Lin CY, Carroll MQ, Miller MJ, Rabot R, Swanson KS. Supplementation of yeast Cell Wall fraction tends to improve intestinal health in adult dogs undergoing an abrupt diet transition. Front Vet Sci. 2020;7:597939.

22. Theodoro S de S, Putarov TC, Tiemi C, Volpe LM, de Oliveira CAF, Glória MB de $A$, et alEffects of the solubility of yeast cell wall preparations on their potential prebiotic properties in dogs. PLoS One 2019;14:e0225659.

23. Swanson KS, Grieshop CM, Flickinger EA, Bauer LL, Healy HP, Dawson KA, et al. Supplemental fructooligosaccharides and mannanoligosaccharides influence immune function, ileal and total tract nutrient digestibilities, microbial populations and concentrations of protein catabolites in the large bowel of dogs. J Nutr. 2002;132:980-9.

24. Fortes CMLS, Carciofi AC, Sakomura NK, Kawauchi IM, Vasconcellos RS. Digestibility and metabolizable energy of some carbohydrate sources for dogs. Anim Feed Sci Technol. 2010;156:121-5. https://doi.org/10.1016/j. anifeedsci.2010.01.009.

25. De-Oliveira LD, Takakura FS, Kienzle E, Brunetto MA, Teshima E, Pereira $\mathrm{GT}$, et al. Fibre analysis and fibre digestibility in pet foods - a comparison of total dietary fibre, neutral and acid detergent fibre and crude fibre. J Anim Physiol Anim Nutr (Berl). 2012;96:895-906.

26. Parvaneh $\mathrm{K}$, Jamaluddin R, Karimi G, Erfani R. Effect of probiotics supplementation on bone mineral content and bone mass density. Sci World J. 2014;595962.

27. Musco N, Calabrò S, Roberti F, Grazioli R, Tudisco R, Lombardi P, et al. In vitro evaluation of Saccharomyces cerevisiae cell wall fermentability using a dog model. J Anim Physiol Anim Nutr (Berl). 2018;102:24-30.

28. Calabrò S, Musco N, Roberti F, Vastolo A, Coppola M, Esposito L, et al. Fermentability characteristics of different Saccharomyces cerevisiae cell wall using cat faeces as inoculum. Ital J Anim Sci. 2020;19:186-93. https:// doi.org/10.1080/1828051X.2019.1710727.

29. Kawauchi IM, Sakomura NK, Vasconcellos RS, De-Oliveira LD, Gomes MOS, Loureiro BA, et al. Digestibility and metabolizable energy of maize gluten feed for dogs as measured by two different techniques. Anim Feed Sci Technol. 2011;169:96-103. https://doi.org/10.1016/j.anifeedsci.2011.05. 005.

30. Beloshapka AN, Duclos LM, Boler BMV, Swanson KS. Effects of inulin or yeast cell-wall extract on nutrient digestibility, fecal fermentative endproduct concentrations, and blood metabolite concentrations in adult dogs fed raw meat-based diets. Am J Vet Res. 2012;73:1016-23.

31. Swanson KS, Grieshop CM, Flickinger EA, Bauer LL, Chow JM, Wolf BW, et al. Fructooligosaccharides and Lactobacillus acidophilus modify gut microbial populations, total tract nutrient digestibilities and fecal protein catabolite concentrations in healthy adult dogs. J Nutr. 2002;132:3721-31.

32. Williams BA, Verstegen MWA, Tamminga S. Fermentation in the large intestine of single-stomached animals and its relationship to animal health. Nutr Res Rev. 2001:14:207-27.
33. Beynen AC, Baas JC, Hoekemeijer PE, Kappert HJ, Bakker MH, Koopman JP, et al. Faecal bacterial profile, nitrogen excretion and mineral absorption in healthy dogs fed supplemental oligofructose. J Anim Physiol Anim Nutr (Berl). 2002;86:298-305.

34. Davila AM, Blachier F, Gotteland M, Andriamihaja M, Benetti PH, Sanz $Y$, et al. Re-print of "intestinal luminal nitrogen metabolism: Role of the gut microbiota and consequences for the host". Pharmacol Res. 2013;69:114-26.

35. Biagi G, Cipollini I, Bonaldo A, Grandi M, Pompei A, Stefanelli C, et al. Effect of feeding a selected combination of galacto-oligosaccharides and a strain of bifidobacterium pseudocatenulatum on the intestinal microbiota of cats. Am J Vet Res. 2013;74:90-5.

36. Ganan M, Carrascosa AV, De Pascual-Teresa S, Martinez-Rodriguez AJ. Effect of Mannoproteins on the growth, gastrointestinal viability, and adherence to Caco-2 cells of lactic acid Bacteria. J Food Sci. 2012;77:M176-80.

37. Musco N, Lombardi P, Calabro S, Mastellone V, Tudisco R, Grossi M, et al. Aloe arborescens supplementation in cat diet: evaluation of effects by in vitro gas production technique. Ital J Anim Sci. 2016;15:407-11.

38. Vernazza CL, Rabiu BA, Gibson GR. Human colonic microbiology and the role of dietary intervention: introduction to prebiotics. In: Gibson GR, Rastall RA, editors. Prebiotics: Development and Application. England: John Wiley \& Sons, Ltd; 2006. p. 1-28.

39. Rutherfurd-Markwick KJ, Hendriks WH, Morel PCH, Thomas DG. The potential for enhancement of immunity in cats by dietary supplementation. Vet Immunol Immunopathol. 2013;152:333-40. https://doi.org/10. 1016/j.vetimm.2013.01.007.

40. AAFCO - Association of American Feed Control Officials. Methods for substantiating nutritional adequacy of dog and cat food. Oxford, Ml; 2014.

41. AOAC. Official methods of analysis of AOAC international. Associatio Gaithersburg. 2006

42. De-Oliveira LD, Carciofi AC, Oliveira MCC, Vasconcellos RS, Bazolli RS, Pereira GT, et al. Effects of six carbohydrate sources on diet digestibility and postprandial glucose and insulin responses in cats. J Anim Sci. 2008:86:2237-46.

43. Walter M, Silva LP, Perdomo DMX. Biological response of rats to resistant starch. Rev Inst Adolfo Lutz. 2005;64:252-7.

44. Pryce JD. A modification of the barker-Summerson method for the determination of lactic acid. Analyst. 1969;94:1151-2.

45. Urrego MIG, Matheus LFO, de Melo SK, Ernandes MC, Monti M, Souza DF, et al. Effects of different protein sources on fermentation metabolites and nutrient digestibility of brachycephalic dogs. J Nutr Sci. 2017;6:E43.

46. Erwin ES, Marco GJ, Emery EM. Volatile fatty acid analyses of blood and rumen fluid by gas chromatography. J Dairy Sci. 1961;44:1768-71.

47. Vale SR, Gloria MB. Determination of biogenic amines in cheese. AOAC Int. 1996;80:1006-12.

48. Carroll IM, Chang YH, Park J, Sartor RB, Ringel Y. Luminal and mucosalassociated intestinal microbiota in patients with diarrhea-predominant irritable bowel syndrome. Gut Pathog. 2010;2:19.

49. Penders J, Vink C, Driessen C, London N, Thijs C, Stobberingh EE. Quantification of Bifidobacterium spp., Escherichia coli and Clostridium difficile in faecal samples of breast-fed and formula-fed infants by real-time PCR. FEMS Microbiol Lett. 2005:243:141-7.

50. Wang RF, Cao WW, Franklin W, Campbell W, Cerniglia CE. A 16 S rDNAbased PCR method for rapid and specific detection of Clostridium perfringens in food. Mol Cell Probes. 1994;8:131-8.

51. Malinen E, Kassinen A, Rinttilä T, Palva A. Comparison of real-time PCR with SYBR green I or 5'-nuclease assays and dot-blot hybridization with rDNA-targeted oligonucleotide probes in quantification of selected faecal bacteria. Microbiology. 2003;149:269-77.

52. Bass DA, Parce JW, Dechatelet LR, Szejda P, Seeds MC, Thomas M. Flow cytometric studies of oxidative product formation by neutrophils: a graded response to membrane stimulation. J Immunol. 1983;130:1910-7.

53. Gill SS, Mueller RW, McGuire PF, Pulido OM. Potential target sites in peripheral tissues for excitatory neurotransmission and excitotoxicity. Toxicol Pathol. 2000;28:277-84.

\section{Publisher's Note}

Springer Nature remains neutral with regard to jurisdictional claims in published maps and institutional affiliations. 